\title{
Hub and spoke model for nursing student placements in the UK
}

\author{
Karen Harrison-White and Elizabeth King explore the many \\ benefits of this approach to clinical practice learning
}

Correspondence

karen.harrison-white@bucks.ac.uk

Karen Harrison White is head of the academic department of children's nursing

Elizabeth King is a senior lecturer in child health

Both at Bucks New University, Uxbridge

Date of submission

July 12014

Date of acceptance

September 22014

Peer review

This article has been subject to open peer review and checked using antiplagiarism software

Author guidelines

journals.rcni.com/r/

ncyp-author-guidelines

\begin{abstract}
The quality of clinical placements is an important factor in nurse education and depends, partly, on the quality of the mentoring. In a hub and spoke model of practice learning, pre-qualifying nursing students are allocated to their placement (hub) in the traditional way and, in addition, are formally supported by their mentor to work in other settings and with different clinicians (spoke experiences) for one week in eight. In a first pilot in three children's wards, participants reported the wide-ranging benefits of this model, which included: a richer learning experience; a heightened sense of belonging; enhanced understanding of the patient journey; greater insight into the roles and responsibilities of the multiprofessional team; and increased awareness of possible career choices. The project's students were able to work more confidently with different clinicians and teams, which should help them become nurses who deliver high quality, modern health care.

\section{Keywords}

Child health, clinical placement, education, nursing, hub and spoke model, nursing students
\end{abstract}

CLINICAL EXPERIENCE is a fundamental part of nurses' pre-qualifying education. In the UK, half of the pre-registration training programme comprises theory-related activities and the remaining time is spent in clinical practice (Nursing and Midwifery Council (NMC) 2010). It is hoped that, through varied clinical experiences and supported learning, students become compassionate, knowledgeable and competent nurses (NMC 2010).

However, clinical placements can appear hostile to learning because of the rapidly changing landscape of health care influenced by the Health and Social Care Act 2012; the increasing acuity of patients (Royal College of Nursing (RCN) 2013); high patient turnover (Dixon 2004); lack of mentors and poor staffing ratios (Jokelainen et al 2011a, RCN 2013); lack of protected time for mentorship activities (Jokelainen et al 2011b); and, at times, poor student-staff relationships (Timmins and Kaliszer 2002, Levett-Jones et al 2009).

This potentially hostile clinical environment heightens the importance of finding new ways to improve learning opportunities and experience in practice. The quality of clinical placements is a major influence on the standard of nurse training, and is supported significantly through the process of mentoring (Chambers 2007).

Aim

This article aims to evaluate and disseminate an experience of implementing a hub and spoke model of student practice experience, across three children's wards in a busy London NHS trust.

\section{'Hub and spoke' model}

Traditionally, nursing students in the UK are allocated to particular placement environments by following a rotational model. Frequently, the placements have no obvious connections between them beyond providing an experience (Roxburgh et al 2012).

Typically, the main drivers behind placement patterns are programme specification and placement availability (Holland et al 2010), rather than specifically addressing learning needs, interests and identified patient pathways. There is often an over-reliance on hospital setting placements, which is at odds with policy imperatives (Roxburgh et al 2012). Traditionally, ad hoc 'extra' opportunities for experience elsewhere, when available, have been offered 
to students while on their placements. However, the number and usefulness of these opportunities have often depended on the motivation of the mentor and student.

A hub and spoke model is one where pre-qualifying nursing students are allocated to their placement (hub) in the traditional way and, in addition, are formally supported by their mentor to work in other settings and with different clinicians (spokes) (NMC 2011). The combination of hub and spoke exposes students to a wider variety of experiences, always with the intention of supporting them in a formalised way to achieve the required NMC (2010) Standards for Pre-registration Nursing Education (Roxburgh et al 2011).

This hub and spoke model is different from the traditional ad hoc 'extra' learning, because the wide-ranging learning mechanism is formalised and therefore accessible to all nursing students.

\section{Reasons for adopting the model} Changing face of nursing in the UK Nursing is a dynamic profession, constantly required to adapt to meet the changing needs of patients and carers against a backdrop of evolving healthcare delivery systems. Nurse leaders are tasked with assuring that a high standard of multidisciplinary care is delivered with compassion (Francis 2013). Nurses are undertaking new roles and responsibilities, working across boundaries and establishing new services (Department of Health (DH) 2006, 2012).

It is, therefore, imperative that pre-qualifying students are exposed to a wide variety of clinical experiences through simulations and practice settings, to equip them to work effectively in this changing arena. For example, there is an increasing move to care for children with complex needs in the community setting, necessitating a greater community workforce.

From the perspective of future workforce planning, it is therefore vital that pre-qualifying nurses have enough clinical exposure to community nursing to present this as a possible career pathway; spoke experiences can enable this.

Pre-registration standards In the UK, the NMC is responsible for approving the provision by universities of pre-qualifying nursing education programmes that lead to NMC registration, and such institutions are called approved education institutions (AEIs). The NMC standards advocate that more flexibility should be built into pre-qualifying practice learning experiences (NMC 2011).
The word 'placement' suggests a fixed length of time in a single environment with distinctive boundaries. Roxburgh et al (2012) suggested that modern practical learning should be patient centred and reflective of the patient's experience and journey, spanning health and social care services. Where AEIs want to introduce a more flexible approach, for example a hub and spoke model, then the NMC (2011) has reiterated that this approach can meet the standard's requirements.

It is vital that the hub mentor is available to students for at least $40 \%$ of their placement time (NMC 2008), and that the mentor supervises the arrangement of the spoke placements and performs the summative assessments. There must be a mechanism for spoke clinicians to feed back their reports to the hub mentor (NMC 2009) about students' learning and behaviours. Conversely, students must be instructed to report to their hub mentor any clinical concerns or other issues that may arise during their spoke experience.

\section{Potential for a richer student experience}

The original driver for implementing this hub and spoke practice model was the authors' local knowledge that children's nursing students were not consistently accessing the wide array of rich learning opportunities available in children's services.

Many learners were unaware that these opportunities even existed; as a consequence, they often did not follow or understand the patient journey, and their experiences were restricted solely to what occurred in their allocated clinical placements.

It was observed that the more confident and dynamic students had the skills to seek out further experiences, but this invariably led to inequity in learning. Newton et al (2009) observed that the way nursing students participated in health care during their clinical placements was crucial to their acquisition of skills and occupational identity, and also to their retention in nursing. Amid the intensity of modern healthcare work, the education of nursing students may easily become restricted (Newton et al 2009); a hub and spoke model can remedy this.

Promotion of interprofessional working Pollard (2008) noted that over the past 20 years there has been international emphasis on improving collaboration in health and social care, with increasing input from policymakers, service managers and educators (World Health Organization (WHO) 1988, NHS Executive 1996, DH 2003, Herbert 2005, McNair et al 2005, Meads et al 2005, WHO 2010). 
In the UK, an additional driver for this policy has been the failings linked with poor interprofessional collaboration in a plethora of high profile children's care cases (Kennedy 2001, Laming 2003, Laming 2009). Reeves et al (2010) argued that interprofessional teamwork can reduce the duplication of work, improve job satisfaction, help the delivery of a streamlined service, and improve patient safety and quality of care (Reeves et al 2010).

Effective interprofessional working can also promote a shared set of appropriate values, attitudes and behaviours across the multidisciplinary team, leading to a high standard of care for patients (Francis 2013).

The authors suggest that a well-organised hub and spoke model of practice experience can give nursing students the opportunity to work interprofessionally and understand the complexities, unique differences and interdependencies of different clinical roles. In addition, it is proposed that this practice experience model could highlight to students the importance of effective communication and collaboration, with the overarching aim of improving the quality of care delivered to patients, including children and their families, in a range of settings.

These propositions are supported by the preliminary findings of Arnott (2010) who undertook a hub and spoke trial in a community setting. In her preliminary findings, the following themes emerged about the benefits of adopting a hub and spoke model:

- Holistic approach to health care.

Interprofessional, interagency working.

Opportunistic intelligence gathering.

In the community, the effects of lifestyle on disease risk.

Placement capacity From the authors' perspective, enhancing pre-qualifying placement capacity through the implementation of hub and spoke experiences was not the main reason for undertaking this initiative. However, as in all AEIs, finding placement capacity is always a challenge, particularly so in the field of child health, as there has been an increase in university competition for diminishing numbers of clinical placements (Finlay et al 2003, Pollard and Hibbert 2003, Smith and Seeley 2010).

\section{Mentors were reminded that students were} supernumerary and that spoke experiences could not be cancelled due to staff shortages
Placement providers are coping with staffing shortages, which affects the availability of suitably trained mentors (Murray and Williamson 2009). Adopting a hub and spoke model of practice experience could potentially lead to an increase in student placement capacity and mentor availability.

\section{Implementation analysis}

Three colleagues (a university link lecturer, clinical nurse educator and NHS trust placement facilitator) worked together on a proposal to organise formal hub and spoke experiences for the children's nursing students. A hub and spoke trial was designed and implemented across three children's wards, with a view to implementing the model trust wide. The trial took place in Imperial College Healthcare NHS Trust; this model continues to be used in the trust and has been extended to other practice areas used by Bucks New University. Children's nursing locations were chosen because these were the link lecturer's area of responsibility. The proposed model was presented to the main stakeholders, who included:

Relevant colleagues in the three universities affiliated with the NHS trust.

The trust managers in adult and children's services.

- The spoke colleagues and hub mentors in the children's clinical areas.

The opinions of the students were also gathered. Without exception, there was overwhelming support for this trial, along with suggestions for further spoke experiences.

After this endorsement, the process was formalised and the required documentation was generated. It was proposed that students on a placement lasting eight weeks or more should be offered one full week of spoke experiences after their mid-point interviews. If students were failing the placement or required an action plan, it was suggested that they should not have a spoke experience week. Either way, they would still participate in ad hoc interprofessional learning activities.

Some participating nursing clinicians required updates because they had not mentored recently in their current roles. Information was sent to all mentors and preparatory talks were held. Some of the spoke experiences involved non-nursing colleagues, who were given information about the hub and spoke model and the curriculum.

The participating students were given the responsibility for organising their own spoke experiences. They were provided with a directory of suggested hospital or community 
experiences linked to their individual placements and to their programme year. Relevant names and contact details were supplied.

The students were advised to arrange experiences that they thought would maximise their individual progress and be relevant to the stage of their training.

They were encouraged by their mentors to make arrangements for hospital and community settings; the community spoke placement could involve either following their own patient through to community services or working with clinicians based in the community.

The students were required to arrange a full 37.5-hour spoke week but, if they were unable to reach this total, they were required to make up the time in the hub placement. They were asked to work in collaboration with their mentors to arrange the week, with the added support of the practice educator and link lecturer.

The students kept a log of their planning and of the spoke week, including hours spent with each clinician and details of the experience. In addition, they completed documentation that outlined their objectives for each spoke experience, and a reflection on the learning that had occurred, and finally they evaluated the week.

The hub mentors and spoke clinicians were also given a guidance pack that outlined their roles and responsibilities in the project. The placement facilitator identified specific spoke week dates for each learner to ensure spoke clinicians were not inundated. The mentors were reminded that the students were supernumerary and that the spoke experiences could not be cancelled due to staff shortages. It was also reiterated that the hub mentor was still the person responsible for assessing the student's progress and for receiving feedback from all learning experiences.

In total, 25 children's nursing students participated in the trial: seven first-year, eight second-year and ten third-year students. The students were purposefully selected because they happened to have placements of a suitable length at the time of the trial. None of them declined to participate or required an action plan.

Some of them arranged many shorter spoke experiences, whereas others arranged whole days in departments or settings in which they were unlikely to be placed otherwise. Some organised additional experiences outside the spoke week, which was fully supported by the mentors. All learners were required to justify their spoke experience choices to their mentors by mapping them to learning outcomes.

\section{Student evaluation}

The students, hub mentors and spoke clinicians gave permission for their experiences to be shared through publication. They gave verbal feedback and the students contributed written feedback. After the spoke week, the students completed a questionnaire comprising a set of open questions that aimed to capture their findings and perceptions. From the answers, it was evident that the spoke arrangements were valued hugely by the students, hub mentors and spoke clinicians.

The emphasis of the responses differed across the three year groups. The first-year students predominantly valued understanding the roles and responsibilities of the various clinicians and the remits of the department. The third-year students evaluated the experience from the standpoint of a nearly qualified nurse and their comments focused principally on areas related to career opportunities and the educational advantages of the hub and spoke model.

\section{Selected quotes from the students}

- 'I am now able to make a decision on which area of nursing I would like to move into post qualification' (year 3 student).

'My experience with the clinicians was amazing, very interesting and informative' (year 1 student).

'This week has enabled me to gain an understanding of some of the roles vital to nursing and the possibilities available post qualification' (year 2 student).

'I felt that the whole week benefited my learning and I enjoyed spending time with different practitioners. I also felt welcomed by the practitioners as they understood the requirements of the hub and spoke week experience' (year 1 student).

- 'I appreciate the opportunities that this week provided me and I think it should become a regular education opportunity for all students' (year 3 student).

The main difficulty the students experienced involved the logistics of arranging their spoke week, in particular contacting the relevant clinicians and diary matching. Although they found this area challenging, they appreciated that their organisational skills had been enhanced in the process. Some of the first-year learners and those who had not worked in the NHS trust before required more support than others from their hub mentor or from the clinical educator in arranging their spoke week.

Following feedback from the first five participants, subsequent students were allowed 
a full morning in their second week to spend time arranging their spoke experiences. This allocated time proved sufficient. Apart from the occasional spoke clinician needing to rearrange their agreed time with the students, due to work pressures, no other major problems were mentioned by the students in their evaluations.

\section{Discussion}

Overwhelmingly, the students reported that the hub and spoke model had enabled them to have a richer practice experience, and that their learning was no longer confined to the opportunities that happened to occur when they were caring for their allocated patients on a particular ward. They chose spoke experiences that they were unlikely to gain in their usual allocation, and this involved either working in different departments or environments, or working with different clinicians; most did both.

The students selected a wide variety of environments including specialist wards, theatres, specialist outpatient clinics, paediatric intensive care and community services. The range of clinicians included nurse specialists in haemoglobinopathy, tuberculosis and human immunodeficiency, family liaison nurses, the outreach team, doctors, pharmacists, play specialists, dieticians, physiotherapists, educationists and safeguarding leads.

The students reported that they benefited from an enhanced understanding of the patient journey, the roles and responsibilities of other clinicians, and the organisation of children's services. Additional benefits were identified through the written evaluations.

Career planning and enhanced understanding of community services Participants reported that some of the spoke experiences revealed specialties of children's nursing of which they had previously not been aware and that they planned to pursue on qualifying.

The effect of placements on students' career planning has been well documented (McKenna et al 2010). By widening the scope, many more potential career pathways could be explored. Although students do have a hub community-based placement in their curriculum, they reported that community spoke experiences enabled them to 'join up' their understanding of community services and identify career pathways in the community.

A sense of belonging The students documented that they experienced a heightened sense of belonging to their hub placements as they travelled to their spoke placements and then returned to their hub.

Levett-Jones and Lathlean (2008) examined the nursing literature and found it infers that reduced levels of belongingness in clinical practice can impede students' motivation for learning, and can influence the degree to which they simply conform rather than adopt a questioning approach to their practice. A sense of belonging is important because it exerts a powerful influence on cognitive processes, emotional wellbeing, behavioural responses and general health and wellbeing, and failure to meet this need can have devastating effects.

Skills enhancement All participants reported on the challenges of arranging the spoke experience week, but they also acknowledged the benefits of improving their organisational and time management skills. They were required to talk directly to and negotiate time with colleagues with whom they were unfamiliar, which improved their communications skills. Learning to communicate with other professional groups is important in laying the foundations for effective interprofessional working (Atwal 2005).

Reiterating the importance of the mentor Jones (2000) asserted that the quality of the professional who guides learning can have a greater effect on attainment than any other single factor. The hub mentors were crucial in enabling the spoke practice experience to occur and for the students to gain the maximum benefit from the week. This process reiterated to the mentors the pivotal role that they play in supporting and maximising student learning in practice (Ousey 2009, Jokelainen et al 2011b).

The mentors respected the learners' supernumerary status and none of the spoke experiences were cancelled due to staff pressures. Supernumerary status is a reality in the curriculum but not always in clinical practice (Allan and O'Driscoll 2011). A hub and spoke model of practice experience has the potential to break the prevailing workforce attitude towards student nurses, when they may been seen merely as a 'pair of hands'. This model highlights that students are required to be released from the ward areas to their spoke placements - they are in practice primarily to learn.

Mentor and placement opportunities By accessing environments that had not traditionally been available to nursing students, a pool of previously untapped resources became available which in time 
could boost placement capacity (Whitehead and Bailey 2006, Pease and Kane 2010).

It is anticipated that some spoke experiences could be translated into additional future child health hub placement opportunities. With each learner on a spoke practice experience for one week out of eight, there is a clear potential for increasing placement capacity by up to $12 \%$.

Students as future mentors The more senior students mentioned in their evaluations that they would have benefited from spoke experience opportunities earlier in their training. It is hoped that the experience of hub and spoke will lead to the students adopting this approach once they become mentors.

\section{Conclusion}

There is no reason why other fields of nursing should not follow this model with the same success. It would be beneficial in future to gain written, rather than verbal, evaluations from the different clinicians. Further formal research should be undertaken to ascertain fully the benefits of this model of practice.

\section{Online archive}

For related information, visit our online archive and search using the keywords

Conflict of interest None declared

\section{References}

Allan HT, O’Driscoll OM (2011) Experiences of supernumerary status and the hidden curriculum in nursing: a new twist in the theory-practice gap? Journal of Clinical Nursing. 20, 5-6, 847-855.

Arnott J (2010) Liberating new talents: an innovative pre-registration community-focused adult nursing programme. British Journal of Community Nursing. $15,11,561-565$.

Atwal A (2005) Do all health and social care professionals interact equally: a study of interactions in multidisciplinary teams in the United Kingdom. Scandinavian Journal of Caring Sciences. 19, 3, 268-273.

Chambers D (2007) Is the modern NHS fit for nursing students? British Journal of Nursing. $16,5,74-75$

Department of Health (2003) Tackling Inequalities. A Programme for Action. DH, London.

Department of Health (2006) Modernising Nursing Careers - Setting the Direction. $\mathrm{DH}$, London.

Department of Health (2012) Liberating the NHS: Developing the Healthcare Workforce. From Design to Delivery. DH, London.

Dixon J (2004) Payment by results - new financial flows in the NHS. British Medical Journal. 328, 7446, 969-970.

Finlay N et al (2003) More nurses: a proposal. Nursing Management. 10, 7, 27-30.

Francis R (2013) The Mid Staffordshire NHS Foundation Trust Public Enquiry.www. midstaffspublicinquiry.com

(Last accessed: February 16 2015.)

Herbert CP (2005) Changing the culture: interprofessional education for collaborative patient-centred practice in Canada. Journal of Interprofessional Care. 19, 1, 1-4.
Holland $\mathrm{K}$ et al (2010) Fitness for practice in nursing and midwifery education in Scotland. Journal of Clinical Nursing. 19, 3-4, 461-469.

Jokelainen M et al (2011a) Building organizational capacity for effective mentorship of pre-registration nursing students during placement learning: Finnish and British mentors' conceptions. International Journal of Nursing Practice. 17, 5, 509-517.

Jokelainen M et al (2011b) A systematic review of mentoring nursing students in clinical placement. Journal of Clinical Nursing. 20 19-20, 2854-2867.

Jones R (2000) Making standards work. American School Board Journal. 1, 87, 27-31. Kennedy I (2001) Learning from Bristol: The Report of the Public Inquiry into Children's Heart Surgery at the Bristol Royal Infirmary 1984-1995. Stationery Office, London.

Laming WH (2003) The Victoria Climbie Inquiry: Report of an Inquiry by Lord Laming. Stationery Office, London.

Laming WH (2009) The Protection of Children in England: a Progress Report. Stationery Office, London.

Levett-Jones T, Lathlean J (2008) Belongingness: a prerequisite for nursing students' clinical learning. Nurse Education in Practice. 36, 2, 103-111.

Levett-Jones T et al (2009) Staff-studen relationships and their impact on nursing students' belongingness and learning. Journal of Advanced Nursing. 65, 2, 316-324.

McKenna L et al (2010) Clinical placements and nursing students' career planning: a qualitative exploration. International Journal of Nursing Practice. 16, 2, 176-182.

McNair R et al (2005) Australian evidence for interprofessional education contributing to effective teamwork preparation and interest in rural practice. Journal of Interprofessional Care. 19, 6, 579-594
Meads G et al (2005) The Case for Interprofessional Collaboration in Health and Social Care. Blackwell, Oxford.

Murray SC, Williamson R (2009) Managing capacity issues in clinical placements for pre-registration nurses. Nurse Education. 18, 22, 3146-3154.

National Health Service Executive (1996) Education and Training Planning Guidance. Stationery Office, London.

Newton JM et al (2009) Journeying through clinical placements - an examination of six student cases. Nurse Education Today. 29, 6, 630-634.

Nursing and Midwifery Council (2008) Standards to Support Learning and Assessment in Practice. NMC, London.

Nursing and Midwifery Council (2009) Additional Information to Support Implementation of NMC Standards to Support Learning and Assessment in Practice. NMC, London.

Nursing and Midwifery Council (2010) Standards for Pre-registration Nursing Education. NMC, London.

Nursing and Midwifery Council (2011) Implementing the Standards for Pre-registration Nursing Education. NMC, London.

Ousey K (2009) Socialization of student nurses - the role of the mentor. Learning in Health and Social Care. 8, 3, 175-184.

Pease S, Kane S (2010) The role of the nurse specialist in placement education. Nursing Standard. 24, 49, 42-46.

Pollard KC (2008) Non-formal learning and inter-professional collaboration in health and social care: the influence of the quality of staff interaction on student learning about collaborative behaviour in practice placements. Learning in Health and Social Care. 7, 1, 12-26.
Pollard C, Hibbert C (2003) Expanding student learning using patient pathways. Nursing Standard. 19, 2, 40-43.

Reeves S et al (2010) Leadership of interprofessional health and social care teams: a socio-historical analysis. Journal of Nursing Management. 18, 3, 258-264.

Royal College of Nursing (2013) Defining Staffing Levels for Children and Young People's Services. RCN Standards for Clinical Professionals and Service Managers. RCN, London.

Roxburgh M et al (2011) The Development Implementation and Evaluation of Demonstration Projects of New Approaches to Providing Practice Placements in the Pre-Registration Nursing Programmes: Contemporising Practice Placements for Undergraduate Student Nurses: Are 'Hub and Spoke Models' the Future?. University of Stirling, Stirling.

Roxburgh M et al (2012) Evaluating hub and spoke modules of practice learning in Scotland, UK: a multiple case study approach. Nurse Education Today. 32, 7, 782-789.

Smith PM, Seeley J (2010) A review of the evidence for the maximisation of clinical placement opportunities through interprofessional collaboration. Journal of Interprofessional Care. 24, 6, 690-698.

Timmins F, Kaliszer M (2002)

Aspects of nursing education programs that frequently cause stress to nursing students. Fact-finding sample survey. Nurse Education Today. 22, 3, 203-211.

Whitehead B, Bailey E (2006) Using specialist nurse mentors to boost placement capacity. Nursing Times. 102, 48, 30-31.

World Health Organization (1988) Learning Together to Work Together. WHO, Geneva.

World Health Organization (2010) Framework for Action on Interprofessional Education and Collaborative Practice. WHO, Geneva. 